\title{
Pleomorphic adenoma with extensive squamous metaplasia and keratin cyst formations in minor salivary gland: a case report
}

\author{
Maria Carolina Vaz GOULART ${ }^{1}$, Patrícia FREITAS-FARIA ${ }^{2}$, Gláuter Rodrigues GOULART ${ }^{3}$, Adriano Macedo de \\ OLIVEIRA ${ }^{4}$, Roman CARLOS-BREGNI ${ }^{5}$, Cleverson Teixeira SOARES ${ }^{6}$, Vanessa Soares LARA ${ }^{7}$
}

\author{
1- DDS, MSc, PhD student, Department of Stomatology (Oral Pathology), Bauru School of Dentistry, University of São Paulo, Bauru, SP, Brazil. \\ 2- DDS, PhD student, Department of Stomatology (Oral Pathology), Bauru School of Dentistry, University of São Paulo, Bauru, SP, Brazil. \\ 3- DDS, Specialist in Oral and Maxillofacial Surgery and Traumatology, Private Practice, Piumhi, MG, Brazil. \\ 4- MD, Specialist in Pathological Anatomy, José do Rosário Vellano University, Unifenas, Alfenas, MG, Brazil. \\ 5- DDS, Director, Division of Pathology, Centro Clinico de Cabeza y Cuello, Guatemala City, Guatemala. \\ 6- MD, Pathologist, Lauro de Souza Lima Institute and Institute of Anatomopathology of Bauru (ANATOMED), Bauru, SP, Brazil. \\ 7- DDS, MSc, PhD, Department of Stomatology (Oral Pathology), Bauru School of Dentistry, University of São Paulo, Bauru, SP, Brazil.
}

Corresponding address: Maria Carolina Vaz Goulart - Faculdade de Odontologia de Bauru - Departamento de Estomatologia - USP - Alameda Octávio Pinheiro Brisolla 9-75 - Vila Universitária - Bauru-SP, Brasil, CEP: 17012-901 - Fone: +55-14-32358251 - Fax: +55-14-32234679 - e-mail: mariacarolinaodonto@ yahoo.com.br

Received: June 19, 2009 - Modification: September 16, 2009 - Accepted: February 16, 2010

\section{ABSTRACT}

\begin{abstract}
Dleomorphic adenoma (PA), the most common salivary gland tumor, accounts for 54 to $65 \%$ of all salivary gland neoplasias and $80 \%$ of the benign salivary gland tumors. It most frequently affects the parotid gland, followed by the submandibular and the minor salivary glands. Microscopically, mucous, sebaceous, oncocytic and squamous metaplasia, sometimes with the formation of keratin pearls, may be present, but the latter rarely results in the formation of extensive keratin-filled cysts lined by squamous epithelium. Extensive squamous metaplasia can be mistaken for malignancy, including mucoepidermoid carcinoma and squamous cell carcinoma. Here, we present an unusual case of PA with extensive squamous metaplasia and keratin cyst formations in a minor salivary gland, and discuss its microscopic features, including the immunohistochemical characteristics, and differential diagnosis of this uncommon presentation.
\end{abstract}

Key words: Pleomorphic adenoma. Diagnosis. Salivary gland neoplasms.

\section{INTRODUCTION}

Pleomorphic adenoma (PA) affecting minor salivary glands presents a female predilection ${ }^{29}$. It occurs over a wide age range, but the mean age is 43.6 years and the peak incidence is between the fourth and fifth decades of life ${ }^{30}$. PA is clinically characterized by a slow growing, sessile-based, firm, painless mass, which occasionally has an ulcerated surface 22 . The most common site for minor salivary gland tumors is the palate ${ }^{4}$.

Microscopically PA exhibits a great diversity of morphological aspects ${ }^{20}$, showing varying combinations of epithelial and myoepithelial cells in a mesenchymal or stromal background. The duct-like formations exhibit ductal luminal cells in the inner layer and abluminal cells (myoepithelial cells and myoepithelial-like cells derived from them) in the outer layer. The capsule varies in thickness and presence, and many tumors show finger-like processes projecting into the capsule ${ }^{13}$. Squamous metaplasia, with the formation of keratin pearls may be present ${ }^{13}$, but rarely results in extensive keratinfilled cysts lined by squamous epithelium $5,7,28$. This microscopic finding may represent a diagnostic dilemma for pathologists.

Wide local excision is recommended as the treatment of choice ${ }^{11}$. Recurrence, which is estimated to occur in $5-30 \%$ of cases, is associated with incomplete surgical excision due to the presence of finger-like tumor extensions outside the capsule or satellite tumors ${ }^{13,22}$. PA presents a risk of malignant transformation, usually giving rise to a carcinoma 
ex pleomorphic adenoma and the frequency of this transformation increases as a result of the tumor persisting without being treated ${ }^{23}$. A close follow-up is necessary postoperatively ${ }^{11}$.

Reports of PA presenting multiple and large squamous epithelium-lined keratin cysts are scarce. Here, we present an unusual case of PA with extensive squamous metaplasia and keratin cyst formations in a minor salivary gland. We discuss the microscopic features, including the immunohistochemical characteristics, and differential diagnosis of this unusual presentation.

\section{CASE REPORT}

A 37-year-old white man presented at the clinic with a 10-year history of a painless mass in the upper vestibule. There was no history of local surgery, trauma, or infection. On intraoral physical examination, there was a soft tissue mass in the right upper vestibule, near lateral incisor and canine teeth. The nodule was movable and firm on palpation (Figure 1). No abnormality was detected on radiographic examination.

A provisional diagnosis of benign salivary gland lesion was made. At surgery, the solid mass was encapsulated, well circumscribed and not adhered to the surrounding tissues, and was easily and completely excised. The specimen was submitted for microscopic examination.

\section{Pathological features}

\section{Histochemistry}

Hematoxylin and eosin (H\&E)-stained sections revealed a well circumscribed encapsulated lesion composed of multiple squamous epithelium-lined

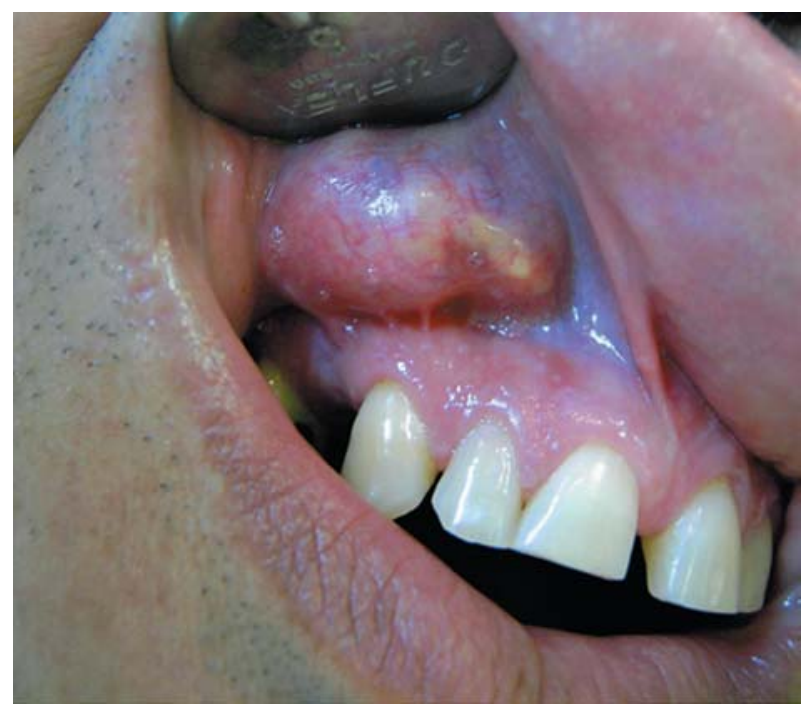

Figure 1- Intraoral photograph at initial examination showing well circumscribed and sessile nodule in the right upper vestibule, measuring $2.0 \mathrm{~cm}$ in diameter and with a normal-appearing oral mucosa surface cysts. The epithelium of the cystic spaces was covered by layers of para- and orthokeratotic cells, usually without a granular layer (Figures $2 \mathrm{~A}$ and $2 \mathrm{~B}$ ). Focally, the outer layer of epithelium demonstrated bud-like protrusions. Scattered and rare mitotic figures were present but limited to the outer layer of the epithelium. The cystic spaces contained keratotic lamellae, which, in some areas, exhibited small calcification foci or cholesterol crystals. Although the cystic structures were variable in size and shape, most of them were large and round. Rare areas of mucous cells were observed in the cystic epithelial lining, which were confirmed by Periodic acid-Schiff (PAS) with or without diastase digestion and Alcian blue stains.

In other areas, tumoral epithelial cells formed solid sheets, nests, cords and ductal structures, the latter presenting a lumina lined by a double layer of cells and frequently containing eosinophilic material (Figures 2D and 2E), which rarely presented small foci of calcification. PAS reactions and Alcian blue staining revealed the presence of mucin inside the ductal structures. The ductal structures occurred in variable sizes and shapes. Some epithelial nests exhibited foci of squamous metaplasia with formations of keratin pearls. In addition, some epithelial nests were formed by clear cells, with scarce central keratin pearls.

The epithelial formations were intermingled with the fibrous stroma (mesenchymal areas), which was characterized by fibrosis and foci of moderate mononuclear inflammatory infiltrate, as well as cholesteatoma and foci of foreign-body giant-cell reaction against keratin material probably caused by the rupture of the cysts. Some fat cells and areas of intense mononuclear inflammatory infiltrate were also identified specially in the periphery of the lesion, which was fully lined by a fibrous capsule, presenting hyperemic blood vessels. No chondroid, osseous, myxoid or mucoid areas were identified within the lesion. These microscopic aspects were suggestive of PA with extensive squamous metaplasia. However, an immunohistochemical study of the lesion was performed to establish the immunoprofile of the neoplastic cells, in order to confirm the initial diagnosis.

\section{Immunohistochemistry}

The reactions were performed using the streptavidin-biotin-peroxidase method. The primary antibodies, their clones and dilutions are summarized in Figure 3. Negative controls were obtained by the omission of primary antibodies, which were substituted by $1 \%$ PBS (phosphate buffered saline)-BSA (bovine serum albumin).

The squamous epithelium covering the keratin cysts was homogeneously positive for highmolecular-weight cytokeratins (Figure 2C). Only 

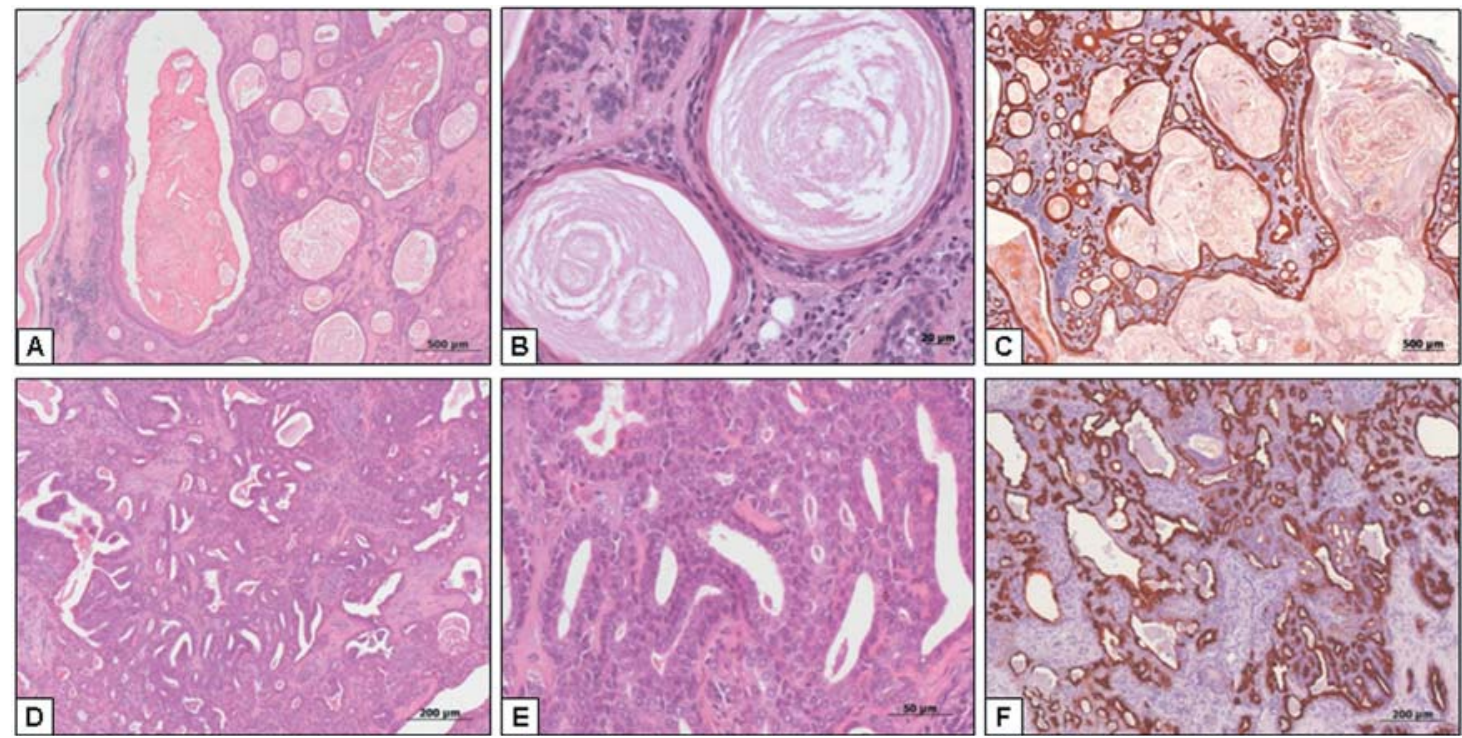

Figure 2- Encapsulated lesion composed of multiple keratin cysts of variable size (A). Cysts lined by stratified squamous epithelium (B), which is intensely positive for high-molecular-weight cytokeratins (CKs; C). Numerous duct-like formations (D), lined by a double layer of cells (E). Intense expression of CK7 in luminal cells of the duct-like structures (F). Hematoxylin and eosin stain $(A, B, D, E)$. Immunoperoxidase stain $(C, F)$

in focal areas of the cystic epithelial lining did cells present immunostaining for CK7, CK19 and EMA in the inner layers, and p63 in the basal layer.

In the ductal structures, the luminal cells were identified by intense and frequent positivity for CK7 (Figures 2F and 4A), CK19 (Figure 4B), EMA and $\mathrm{S}-100$, as well as focal immunostaining considered moderate for CK8 (Figure 4C) and intense for both polyclonal and monoclonal antibodies to CEA. Some abluminal cells were frequently positive for myoepithelial cell markers such as high-molecularweight CKs (Figure 4D), p63 (Figure 4E), S-100 and vimentin (Figure 4F), and occasionally for SMA, MSA and GFAP. The luminal and abluminal cells, i.e. glandular phenotype-cells, were negative for CK20.

Solid sheets, nests and cords presented immunopositivity that was either focal for CK7, CK19, vimentin, GFAP and S-100, or frequent for high-molecular-weight CKs. Cells in the basal layer of the epithelial cords were positive for p63.

The epithelium lining the cysts and the solid areas were surrounded by collagen IV-positive material. The proliferative index of the lesion, expressed as the percentage of Ki-67-positive neoplastic cells among the total number of cells counted in 10 randomly selected fields, was low $(2.63 \%)$ and proliferation was mainly localized in the outer layers of the epithelial lining of the large keratin cysts. Expression of p53 was observed in rare neoplastic cells, throughout the lesion.

The mesenchymal areas presented S-100- and vimentin-positive cells and the blood vessels were collagen IV-, MSA-, SMA- and vimentin-positive. Most inflammatory cells were Ki-67 positive. The immunohistochemical features of the lesion are summarized in Figure 5.

Considering the morphological and

\begin{tabular}{|l|c|c|}
\hline Antibody Specificit & Clone & Dilution \\
\hline CK7* & OV-TL12/30 & $1: 200$ \\
\hline CK8* & $35 \beta H 11$ & $1: 150$ \\
\hline CK19** & B170 & $1: 100$ \\
\hline CK20* & KS20.8 & $1: 50$ \\
\hline Hmw CKs $^{*}$ & $34 \beta E 12$ & $1: 200$ \\
\hline EMA $^{*}$ & E29 & $1: 200$ \\
\hline CEA $^{*}$ & $11-7$ & $1: 200$ \\
\hline CEA $^{*}$ & Polyclonal & $1: 400$ \\
\hline GFAP $^{*}$ & $6 F 2$ & $1: 100$ \\
\hline S-100* & COW S-100 & $1: 1400$ \\
\hline SMA $^{*}$ & 1 A4 & $1: 200$ \\
\hline MSA $^{*}$ & HHF35 & $1: 5000$ \\
\hline p63 $^{*}$ & $4 A 4$ & $1: 150$ \\
\hline Vimentin* $^{*}$ & V9 & $1: 400$ \\
\hline Collagen IV* $^{*} 53^{*}$ & CIV22 & $1: 80$ \\
Ki-67* $^{*}$ & DO-7 & $1: 50$ \\
\hline
\end{tabular}

CK (cytokeratin), Hmw (high-molecular-weight), EMA (epithelial membrane antigen), CEA (carcinoembryonic antigen), GFAP (glial fibrillary acidic protein), SMA (smooth muscle actin), MSA (muscle specific actin) Source: * Dako, Carpinteria, CA, USA

${ }^{* *}$ Novocastra Laboratories Ltd, Newcastle, UK

Figure 3- List of antibodies used for immunohistochemical staining 

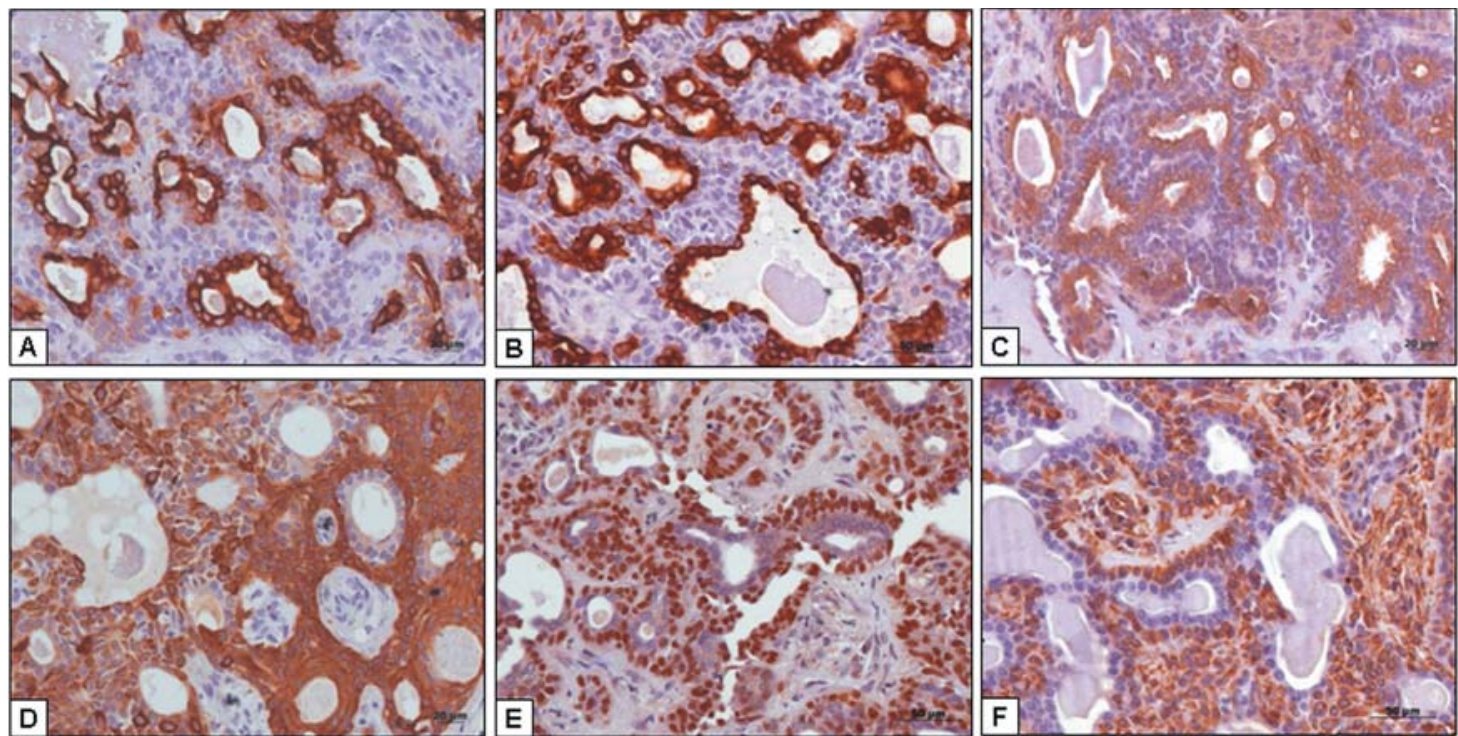

Figure 4- Immunoprofile of duct-like structures. Luminal cells intensely positive for cytokeratin (CK) 7 (A) and CK19 (B) and moderately positive for CK8 (C). Abluminal cells moderately positive for high-molecular-weight (CKs) (D), p63 (E) and vimentin $(F)$. Immunoperoxidase stain

\begin{tabular}{|c|c|c|c|c|c|}
\hline Antibody Specificity & Cystic lining & Luminal cells & Abluminal Cells & Solid areas & Mesenchymal cells \\
\hline CK7 & +++ & +++ & - & +++ & - \\
\hline CK8 & - & ++ & - & - & - \\
\hline CK19 & +++ & +++ & - & +++ & - \\
\hline CK20 & - & - & - & - & - \\
\hline Hmw CKs & +++ & - & ++ & +++ & - \\
\hline EMA & +++ & +++ & - & - & - \\
\hline CEA(mono) & - & +++ & - & - & - \\
\hline CEA (poly) & - & +++ & - & - & - \\
\hline GFAP & - & - & +++ & +++ & - \\
\hline S-100 & - & +++ & ++ & +++ & +++ \\
\hline SMA & - & - & + & - & - \\
\hline$\overline{M S A}$ & - & - & + & - & - \\
\hline p63 & +++ & - & ++ & +++ & - \\
\hline Vimentin & - & - & ++ & +++ & +++ \\
\hline
\end{tabular}

Immunostaining was graded as (-) negative; $(+)$ weakly positive; $(++)$ moderately positive; $(+++)$ strongly positive

Figure 5- Immunohistochemical features of the neoplastic cells

\begin{tabular}{|l|c|c|c|c|c|c|c|c|c|c|c|c|c|c|}
\hline \multicolumn{10}{|c|}{ Antibody Specificity } \\
\hline Lesion & CK 7 & CK 8 & CK 19 & CK 20 & Hmw CKs & EMA & CEA & GFAP & S-100 & SMA & MSA & p63 & Vim \\
\hline PA & + & + & + & - & + & + & + & + & + & + & + & + & + \\
\hline MEC & + & + & + & - & + & + & a & + & - & - & - & a & - \\
\hline SCC & - & + & $\mathrm{a}$ & - & + & + & + & $\mathrm{Nf}$ & - & - & $\mathrm{nf}$ & $\mathrm{a}$ & - \\
\hline KC & + & - & + & $\mathrm{nf}$ & $\mathrm{nf}$ & $\mathrm{nf}$ & $\mathrm{nf}$ & $\mathrm{Nf}$ & - & - & $\mathrm{nf}$ & $\mathrm{nf}$ & $\mathrm{nf}$ \\
\hline
\end{tabular}

PA (Pleomorphic adenoma), MEC (Mucoepidermoid carcinoma), SCC (Squamous cell carcinoma), KC (Keratocystoma), Vim (Vimentin)

(-) negative; (+) positive; (a) variable expression; (nf) data not found

Figure 6- Immunohistochemical features of the lesions included in the differential diagnosis of PA with extensive squamous metaplasia 
immunohistochemical findings a final diagnosis of PA with extensive squamous metaplasia was made. The postoperative course was uneventful and the patient has been reviewed regularly, with no evidence of recurrence 3 years after excision.

\section{DISCUSSION}

PA presenting extensive squamous metaplasia is uncommon ${ }^{7}$ and can signify a potential pitfall in the histopathological diagnosis.

Focal squamous metaplasia, probably related to ischemia ${ }^{16}$, may be present in about $25 \%$ of the $\mathrm{PA}^{24}$. The cases of PA presenting extensive keratin-filled cysts lined by squamous epithelium are referred to in the literature as "cystic PA with extensive adnexa-like differentiation", since the histologic features mimic cutaneous appendages 7,25 . In our case, many glandular cells were transformed into squamous cells through a process of squamous metaplasia, resulting in multiple squamous epithelium-lined cysts containing keratotic lamellae and some solid squamous cell islands presenting keratin pearls. The epithelium lining the keratin cyst formations was homogeneously positive for a set of high-molecular-weight CKs, commonly expressed in squamous epithelium, while some cells presented immunostaining for p63, EMA and low-molecular-weight CKs (CK7 and CK19), representing glandular cells which probably had not yet undergone squamous metaplasia.

Extensive squamous metaplasia in PA, especially in the absence of chondromyxoid stroma, can mistakenly lead to a diagnosis of benignity, such as choristoma24 or keratocystoma21, and malignancy13, including mucoepidermoid carcinoma (MEC) and squamous cell carcinoma, especially when sampling the tissue by fine-needle aspiration biopsy (FNAB) and incisional biopsy, due to limited and selective sampling5,7,12,16,26. It is important to discuss the diagnostic pitfall of this unusual presentation of a common benign entity, particularly the differential diagnosis with these malignant lesions.

Microscopically, MEC presents mucous, intermediate and squamoid (epidermoid) cells and is usually multicystic. Unlike our case, the cystic spaces of MEC are usually lined by mucous cells and prominent keratinization is rare ${ }^{13}$, with scarce epidermoid cells associated with keratin production including keratin pearl formation ${ }^{8,15}$. Furthermore, the presence of a fibrous capsule in our case favors the diagnosis of a benign lesion. In addition to the above mentioned morphological findings, the immunopositivity for S-100, SMA and vimentin found in the reported lesion could help to exclude the diagnosis of $\mathrm{MEC}^{3,17,19}$. Regarding the differential diagnosis with squamous cell carcinoma, the absence of cytological atypia, metastasis, necrosis, invasion, as well as minimal cellular proliferative activity and the presence of a fibrous capsule in the case presented here weigh against the diagnosis of malignancy. Moreover, the neoplastic cells of CEC, differently from PA, are immunonegative for CK7, S100, SMA and vimentin ${ }^{10,18}$.

A choristoma resembling a trichoadenoma (a type of hair follicle tumor), described in the parotid gland by Seifert, Donath and Jautzke ${ }^{24}$ (1999), also presents multiple cystic spaces limited by a multilayered squamous epithelium and filled with keratotic lamellae. It also exhibits solid squamous cell islands, keratinized masses outside the cysts with multinucleated giant cells and focal calcification. Nagao, et al. ${ }^{21}$ (2002) described two cases histologically identical to the choristoma previously reported, both of the parotid gland, but the authors proposed a new designation for the lesions: keratocystoma, since they believe that the choristoma described by Seifert, Donath and Jautzke $^{24}$ (1999) is a peculiar variety of salivary gland tumor. Although our case presents similar morphological aspects to those described for choristoma ${ }^{24}$ or keratocystoma ${ }^{21}$, these lesions are mainly composed of squamous cells and lack the neoplastic structures with glandular phenotype, including duct-like formations and myoepithelial cells, which were demonstrated in our case by means of morphology and immunohistochemistry. Moreover, the cystic spaces of the keratocystoma are lined by a stratified squamous epithelium without a granular cell layer ${ }^{21}$, unlike our case, which showed some areas of granular layers. Similar to our findings, the squamous cells lining the cystic formations were negative for CK8, focally immunoreactive for CK19, and surrounded by collagen-IV material. Based on the morphological aspects, we are inclined to believe that the PA reported here and the keratocystoma may constitute related lesions, representing different stages in the evolution of a specific type of salivary gland tumor, although the latter previously demonstrated immunonegativity for S100 and $S_{M A}{ }^{21}$. Immunohistochemical features of the lesions included in the differential diagnosis of PA with extensive squamous metaplasia are included in Figure 6.

The immunohistochemical analysis of the current case helped to define the nature of the tumor cells, adding support to the diagnosis of PA. It identified the luminal cells of the duct-like structures by immunopositivity for low-molecular-weight CKs, including CK7, CK8 and CK19, as well as CEA and $\mathrm{EMA}^{9}$, whereas the abluminal cells were identified by heterogeneous positivity for myoepithelial cell markers such as p63, high-molecular-weight CKs, S-100, vimentin, SMA, MSA and GFAP. This 
immunoprofile of the luminal and abluminal cells of the duct-like formations observed is similar to those described in other articles in the literature ${ }^{9,14}$. In addition to the abluminal cells, the luminal cells were also positive for S-100, which is in agreement with the findings of other authors ${ }^{14}$.

The solid sheets, nests and cords presented immunoreactivity either for CK7 and CK19, suggesting a luminal cell phenotype, or for vimentin, GFAP and p63, in this case demonstrating a myoepithelial cell phenotype. Although not accompanied by myxochondromatous elements, the glandular phenotypic profile associated with the morphological features reinforces the diagnosis of PA. Degrees of stromal changes, such as chondroid, osseous, myxoid or mucoid changes vary widely in $\mathrm{PA}^{6,13}$, however the absence of these changes, as in our case, is an unusual finding.

Ki-67 expression was sporadic $(2.63 \%)$, which is consistent with the literature data describing PA as having a low proliferative rate ${ }^{2,27}$. Interestingly, the epithelial lining of the large keratin filled cysts presented a higher proliferative index than the other areas. It may signify that the squamous metaplasia resulting in large keratin filled cysts in PA may be clinically significant, probably related to an important growth potential, although our data are insufficient to support this hypothesis. Further studies are required to clearly establish this relationship. Our case, as also indicated in previous reports ${ }^{1,2}$, presented scarce p53-positive cells, which are associated with changes in the apoptotic mechanism.

\section{CONCLUSION}

In conclusion, the localization, gender and microscopic features of the presented case are unusual. PA with extensive squamous metaplasia and keratin cyst formations can pose a significant diagnostic challenge. It is important to be aware of this possibility to distinguish it from malignant lesions and to avoid unnecessarily aggressive therapy. The morphological features, as discussed above, must be carefully evaluated in order to exclude other lesions and to define the diagnosis of PA. Additionally, the immunohistochemical analysis, in addition to establishing the nature of the tumor cells, may also be helpful for the differential diagnosis, reinforcing the morphological diagnosis, especially when PA has an unusual presentation.

\section{ACKNOWLEDGMENTS}

The authors are grateful to Fátima Aparecida Silveira (Department of Stomatology, Bauru School of Dentistry, University of São Paulo), Daniel de Amorim and Éverson Moretti (Institute of
Anatomopathology of Bauru - ANATOMED) for their technical support and Gareth Cuttle and Margery Galbraith for their English language services in copy editing the manuscript.

\section{REFERENCES}

1- Al-Rawi NH, Omer H, Al Kawas S. Immunohistochemical analysis of $\mathrm{P}(53)$ and bcl-2 in benign and malignant salivary glands tumors. J Oral Pathol Med. 2010;39(1):48-55.

2- Alves FA, Pires FR, Almeida OP, Lopes MA, Kowalski LP. PCNA, Ki67 and p53 expressions in submandibular salivary gland tumours. Int J Oral Maxillofac Surg. 2004;33:593-7.

3- Araújo VC, Souza SOM, Carvalho YR, Araújo NS. Application of immunohistochemistry to the diagnosis of salivary gland tumors. Appl Immunohistochem Mol Morphol. 2000;8:195-202.

4- Bablani D, Bansal S, Shetty SJ, Desai R, Kulkarni SR, Prasad $P$, et al. Pleomorphic adenoma of the cheek: a case report and review. J Oral Maxillofac Surg. 2009;67:1539-42.

5- Batrani M, Kaushal M, Sen AK, Yadav R, Chaturvedi NK. Pleomorphic adenoma with squamous and appendageal metaplasia mimicking mucoepidermoid carcinoma on cytology. Cytojournal. 2008;6:5.

6- Bento PM, Freitas R de A, Pinto LP, Souza LB. Tenascin and fibronectin in pleomorphic adenoma of the salivary gland. J Appl Oral Sci. 2006;14:198-202.

7- Brachtel EF, Pilch BZ, Khettry U, Zembowicz A, Faquin WC. Fine-needle aspiration biopsy of a cystic pleomorphic adenoma with extensive adnexa-like differentiation: differential diagnostic pitfall with mucoepidermoid carcinoma. Diagn Cytopathol. 2003;28:100-3.

8- Brandwein MS, Ivanov K, Wallace DI, Hille JJ, Wang B, Fahmy A, et al. Mucoepidermoid carcinoma: a clinicopathologic study of 80 patients with special reference to histological grading. Am J Surg Pathol. 2001;25:835-45.

9- Cheuk W, Chan JK. Advances in salivary gland pathology. Histopathology. 2007;51:1-20.

10- Coletta RD, Cotrim P, Almeida OP, Alves VA, Wakamatsu A, Vargas PA. Basaloid squamous carcinoma of oral cavity: a histologic and immunohistochemical study. Oral Oncol. 2002;38:723-9.

11- Dalati T, Hussein MR. Juvenile pleomorphic adenoma of the cheek: a case report and review of literature. Diagn Pathol. $2009 ; 4: 32$.

12- Daneshbod Y, Daneshbod K, Khademi B. Diagnostic difficulties in the interpretation of fine needle aspirate samples in salivary lesions: diagnostic pitfalls revisited. Acta Cytol. 2009;53:53-70. 13- Eveson JW, Auclair P, Gnepp DR, El-Naggar AK. Tumours of the salivary glands. In: Barnes L, Eveson JW, Reichart P, Sidransky $D$, editors. World Health Organization Classification of Tumours. Pathology and Genetics of Head and Neck Tumours. Lyon: IARC Press; 2005. p. 209-81.

14- Furuse C, Sousa SO, Nunes FD, Magalhães MH, Araújo VC. Myoepithelial cell markers in salivary gland neoplasms. Int J Surg Pathol. 2005;13:57-65.

15- Guo SP, Cheuk W, Chan JK. Pleomorphic adenoma with mucinous and squamous differentiation: a mimicker of mucoepidermoid carcinoma. Int J Surg Pathol. 2009;17:335-7.

16- Hamdan K, Maly B, Elashar R, Gross M. Mucinous and squamous metaplasia in benign tumors of the parotid gland: a potential pitfall in the diagnosis. Otolaryngol Head Neck Surg. 2005;133:987-8.

17- Hamper K, Schmitz-Wätjen W, Mausch HE, Caselitz J, Seifert G. Multiple expression of tissue markers in mucoepidermoid carcinomas and acinic cell carcinomas of the salivary glands. Virchows Arch A Pathol Anat Histopathol. 1989;414:407-13.

18- Kawashiri S, Tanaka A, Noguchi N, Hase T, Nakaya H, Ohara $T$, et al. Significance of stromal desmoplasia and myofibroblast appearance at the invasive front in squamous cell carcinoma of 
the oral cavity. Head Neck. 2009;31:1346-53.

19- Loyola AM, Sousa SO, Araújo NS, Araújo VC. Study of minor salivary gland mucoepidermoid carcinoma differentiation based on immunohistochemical expression of cytokeratins, vimentin and muscle-specific actin. Oral Oncol. 1998;34:112-8.

20- Margaritescu C, Raica M, Florescu M, Simionescu C, Surpateanu $M$, Jaubert $F$, et al. The ultrastructural aspects of neoplastic myoepithelial cell in pleomorphic adenomas of salivary glands. J Cell Mol Med. 2004;8:369-81.

21- Nagao T, Serizawa H, Iwaya K, Shimizu T, Sugano I, Ishida $Y$, et al. Keratocystoma of the parotid gland: a report of two cases of an unusual pathologic entity. Mod Pathol. 2002;15:1005-10.

22- Pons Vicente O, Almendros Marqués N, Berini Aytés L, Gay Escoda C. Minor salivary gland tumors: a clinicopathological study of 18 cases. Med Oral Patol Oral Cir Bucal. 2008;13:E582-8.

23- Rodríguez-Fernández J, Mateos-Micas M, Martínez-Tello FJ, Berjón J, Montalvo JJ, Forteza-González G, et al. Metastatic benign pleomorphic adenoma. Report of a case and review of the literature. Med Oral Patol Oral Cir Bucal. 2008;13:E193-6.

24- Seifert G, Donath K, Jautzke G. Unusual choristoma of the parotid gland in a girl. A possible trichoadenoma. Virchows Arch. 1999;434:355-9.

25- Siddaraju N, Murugan P, Basu D, Verma SK. Preoperative cytodiagnosis of cystic pleomorphic adenoma with squamous metaplasia and cholesterol crystals: a case report. Acta Cytol.
2009;53:101-4.

26- Siddiqui NH, Wu SJ. Fine-needle aspiration biopsy of cystic pleomorphic adenoma with adnexa-like differentiation mimicking mucoepidermoid carcinoma: a case report. Diagn Cytopathol. $2005 ; 32: 229-32$.

27- Soares AB, Araújo VC, Juliano PB, Altemani A. Angiogenic and lymphangiogenic microvessel density in recurrent pleomorphic adenoma. J Oral Pathol Med. 2009;38:623-9.

28- Stewart CJ, MacKenzie K, McGarry GW, Mowat A. Fine-needle aspiration cytology of salivary gland: a review of 341 cases. Diagn Cytopathol. 2000;22:139-46.

29- Vargas PA, Gerhard R, Araújo Filho VJ, Castro IV. Salivary gland tumors in a Brazilian population: a retrospective study of 124 cases. Rev Hosp Clin Fac Med Sao Paulo. 2002;57:271-6.

30- Wang D, Li Y, He H, Liu L, Wu L, He Z. Intraoral minor salivary gland tumors in a Chinese population: a retrospective study on 737 cases. Oral Surg Oral Med Oral Pathol Oral Radiol Endod. 2007;104:94-100. 